\title{
PROFESSOR ROBERT SCHALLER: ZENER MEDALIST
}

The following is the text of an oral presentation delivered at the Zener Medal Award ceremony in Hefei on 23 September 2015.

Keywords: internal friction, mechanical spectroscopy, the Zener Price

Robert Schaller was born on a 21 July 1948 in Delémont, Switzerland. It was a key year for internal friction and mechanical spectroscopy since in that year Clarence Zener published the first comprehensive work on internal friction: Elasticity and Anelasticity of Metals. Most of the future themes of investigation of mechanical spectroscopy are there: point defect relaxations of Snoek and Zener type, magnetic and thermoelastic relaxations, phase transformations, twin boundary and grain boundary relaxations, and in particular the work by Dr. Ting Sui Kê. The book was published at the University of Chicago where three institutes were established: the Institute of Nuclear Physics, the Institute of Biophysics, and the Institute for the Study of Metals directed by Clarence Zener. Metallurgy was promoted at the level of Science. One could notice that the clear vision of the University was to promote the interaction between multiple scientific disciplines at the interface between chemistry and physics. Robert grew up with interfaces. Looking at a map of Jura, cantons and countries are deeply interpenetrated like grains in a metal. But the Jura mountains are also the heart of Swiss metallurgy: foundries and machine tool in Moutier, copper foundries in Reconvillier and all activities connected with the watch industry. And Basel, where all chemical and pharmaceutical industry is concentrated, is just $40 \mathrm{~km}$ from Delémont.

Robert was good in math and decided to undertake physics studies at the Swiss Federal Institute of Technology (EPFL). It was 1969 and man made his first steps on the moon. During that time, in 1972 the book by A.S. Nowick and B.S. Berry was published. This book remains the foundation of a Science that since Zener approach had become mature. Robert got his diploma at EPFL in 1974 working under the supervision of B. Vittoz in the laboratory where he was destined to spend his whole career. It was the year when W. Benoit was appointed professor and it was just the moment where the new modern site of the Frenchspeaking Institute of Technology was being built in Lausanne. Robert was able to enjoy during his $\mathrm{PhD}$ thesis the glorious time during which Prof. Vittoz was director of the Institute of Atomic Physics. Robert Schaller did his PhD work under the directorship of Prof. Willy Benoit (Zener medalist, 2002) who undertook the direction of the Institute when Prof. Vittoz became the Director of EPFL. Prof. Benoit always told me that the Institute had two souls: a theoretical one from Gerard Gremaud (Zener medalist, 2011) and one applied from Robert Schaller. Indeed, Robert was the interface between academic science and industrial applications. His $\mathrm{PhD}$ work was about the 'Precipitation stages in Al-Ag alloys'. R. Schaller was able to determine that in such concentrated alloys, Zener-type peaks appear. As a young researcher he was not afraid of masters and boldly contradicted Schoek's hypothesis about the existence of a peak originating at the interface between precipitates and the matrix. He clearly showed that the peak was in the precipitate. Then he started to work with other types of precipitates co-directing the thesis of P. Millet on grey cast iron. Again, the damping originated from the graphite precipitates. The project originated from Von Roll foundries in Moutier not far from the home town of Robert Schaller. When I met him in 1986, I was almost heading towards theoretical physics when he proposed to me a $\mathrm{PhD}$ thesis on WC-Co, a messy material at the border between ceramics and metals, what we would call a cermet. I had sold my soul to physics of dirt ! Instead, I strongly believe as Robert does, that it is in this direction that the future of mechanical spectroscopy is wide open.

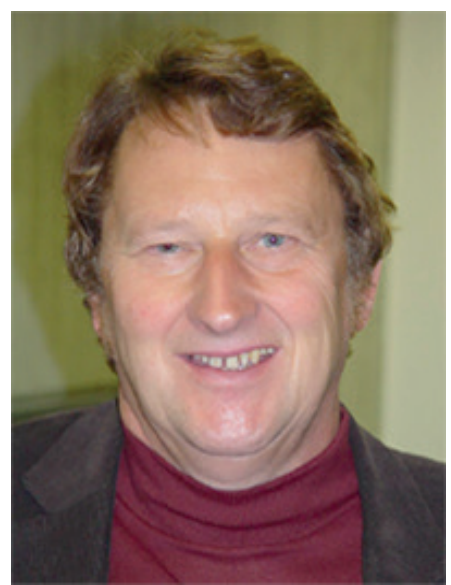

Professor Robert Schaller

* ECOLE POLYTECHNIQUE FÉDÉRALE DE LAUSANNE, INSTITUTE OF CONDENSED MATTER PHYSICS, STATION 3, CH-1015 LAUSANNE, SWITZERLAND

\# Corresponding author: daniele.mari@epfl.ch 
At that time, the spectrum of WC-Co just showed one peak located in the cobalt phase that is key for the composite toughness. We did not have the means to know what happens at temperatures higher than $900^{\circ} \mathrm{C}$. However, in tools made of $\mathrm{WC}-\mathrm{Co}$ and ceramic materials, the working temperature is much higher. R. Schaller was at the origin of the construction of a new generation of pendula: Forced- and High-temperature ones. This technological step promoted a new subject where the expertise of the EPFL group has been recognized worldwide to date: ceramics. In particular, ceramics deform at high temperature by grain boundary sliding. Only the combination of forced very low frequency oscillations and high temperatures allowed the discovery of grain boundary peaks in zirconia and silicon nitride. However, hindering grain boundary sliding, thereby making more refractory materials for high temperature mechanical applications implies blocking the grain boundaries. This attempt to reinforce grain boundaries was finally successful with the thesis of M. Mazaheri who decided to add carbon nanotubes in the boundary and obtained an extraordinary material that combines high toughness with resistance to deformation at high temperature, manifested by a decrease in the internal friction background. Notice that in 2001, at the dawn of the new millennium, Robert Schaller marked the state-of-the-art of mechanical spectroscopy with a summer school and a new book that collected the work of some of the most representative experts in the field.

Grain boundary sliding in metals has been the subject of a long controversy in the community since the model of Zener and the first discovery of a grain boundary peak in aluminum by T.S. Kê. Effectively, direct proofs of grain boundary sliding in metals are rare and it has been often argued that dislocations (possibly in grain boundaries) are responsible for this peak. Robert participated in the debate without really taking a clear position. He was convinced of the existence of a grain boundary peak when co-directing the thesis of B. Cao (from China) on a project launched from the USA. This has been since then a recurrent theme of research until the present day. In one of the presentations of this conference from the last $\mathrm{PhD}$ student of Robert (A.K. Audren), some of the mysteries of GBS in metals will be disclosed. Such work concerns gold alloys. Precious metals are key materials for the watch industry that has been so important to Swiss tradition and economy, in particular for the region from where Robert Schaller comes from. Therefore, there is nothing more appropriate than celebrating with a gold medal such a long adventure that started with Clarence Zener.

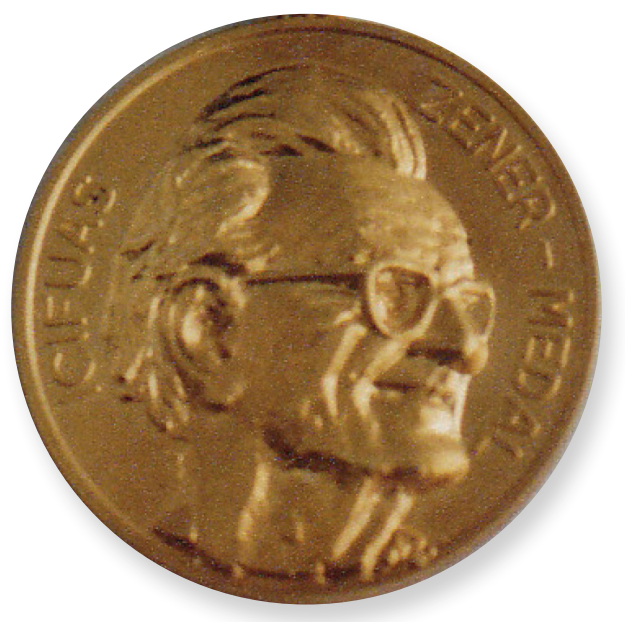

The Zener Medal awarded to Professor Robert Schaller 